\title{
Therapeutic hypothermia after cardiac arrest - a survey of the use in Denmark Mikkel Brabrand ${ }^{* 1}$ and Nicola Groes Clausen ${ }^{2}$
}

\author{
Address: ${ }^{1}$ Department of Cardiology, Odense University Hospital, Denmark and ${ }^{2}$ Department of Anesthesia, Sygehus Lillebælt, Kolding, Denmark \\ Email: Mikkel Brabrand* - mikkel@brabrand.net \\ * Corresponding author
}

from Danish Society for Emergency Medicine: Research Symposium 2009

Copenhagen, Denmark. 26 April 2009

Published: 20 August 2009

Scandinavian Journal of Trauma, Resuscitation and Emergency Medicine 2009, I7(Suppl 2):PII doi:I0.II86/I757-724I-I7-S2-PII

This abstract is available from: http://www.sjtrem.com/content/I7/S2/PI I

(c) 2009 Brabrand and Clausen; licensee BioMed Central Ltd.

\section{Introduction}

Anoxia causes brain injury. Various studies suggest that mild therapeutic hypothermia (TH) improves neurologic outcome after successfully resuscitated cardiac arrest.

Previous studies have indicated that the uptake of TH by intensive care units (ICU) around the world is poor although recommendations supporting the use of $\mathrm{TH}$ have been published. We designed an internet-based survey in order to reveal the routine at ICU's in Denmark.

\section{Methods}

An introduction to the study and an individual link to the survey were emailed to department heads of Danish ICU's.

Questions were asked on the demography of the hospital and ICU, the use of TH, methods employed, reasons why they had not incorporated TH and whether the center had composed a standard operation procedure (SOP).

ICU's who did not respond to our enquiry received reminders, three at the most.

\section{Results}

Of 32 ICU's, 19 completed the survey (59\%), one was excluded as the hospital did not receive emergency admissions. The hospitals had a mean of 374 beds and the ICU's had a mean of 9.4 beds. Three hospitals had an invasive cardiology department.
Seventeen departments (94\%) had introduced $\mathrm{TH}$; the first department introduced it in 2002. The number of patients treated with TH ranged between "a few" and 250 . Five $(29 \%)$ departments began TH in the pre-hospital phase, seven in the emergency department (41\%) and five in the ICU (29\%).

Three departments (18\%) offered TH only to patients with VF/VT as the initial rhythm. Thirteen departments $(76 \%)$ offered TH regardless of presenting rhythm and one $(6 \%)$ was unanswered. Sixteen had a SOP for TH (94\%).

None of the departments has a structured follow-up procedure for these patients and only one department $(6 \%)$ participated in a multicenter database on the use of TH.

\section{Conclusion}

At 17 ICU's in Denmark, mild therapeutic hypothermia after cardiac arrest is implemented as a standard treatment. Thirteen ICU's chose not to participate in this study, therefore we do not have complete data of the use of $\mathrm{TH}$ at ICU's in Denmark. 